\title{
Heterotopic Implantation of Fetal Heart in Syngeneic Adult Rats (Comparative Study of Growth Conditions, Limits and Perspectives)
}

\author{
CoulicVéry ${ }^{* 1}$, QuéronS ${ }^{1}$, Najar ES ${ }^{2}$, Hermanus ${ }^{2}{ }^{2}$, De PrezC ${ }^{3}$ and DelréeP ${ }^{4}$ \\ ${ }^{1}$ ULB Laboratory of Translational Research, Belgium
}

${ }^{2}$ CHU Brugmann, Department of Medical Imaging, Belgium

${ }^{3} \mathrm{CHU}$ Brugmann, Department of Pathological Anatomy and Medical Imaging, Belgium

${ }^{4}$ Institute of Pathology and Genetics, Belgium

*Corresponding author: Coulic Véry, Laboratory of Translational Research; 2 Avenue JJ Crocq, B1020 Brussels, Belgium.

To Cite This Article: CoulicVéry, QuéronS, Najar ES, Hermanus N, De PrezC, DelréeP, Heterotopic Implantation of Fetal Heart in Syngeneic Adult Rats(Comparative Study of Growth Conditions, Limits and Perspectives). Am J Biomed Sci \& Res. 2020 - 7(1). AJBSR.MS.ID.001116. DOI: 10.34297 /AJBSR.2020.07.001116.

Received: 㘹 January 20, 2020; Published: 䟧 January 28, 2020

\begin{abstract}
Background: In spite of the official ending of the moratorium about foetus and foetal material use for scientific purpose, foetal organ transplantation remains weakly investigated though it represents a culture in vivo of developing cells, tissues, organs. The present work aims at exploring technical and developmental aspects of such a study applied to the foetal heart heterotopic implantation.

Material and methods: 130 rats of both sexes and different strains (Wistar and Fischer) were used for syngeneic implantation of foetal heart into different sites (intra thoracic, intra peritoneal, subcutaneous) of adult organisms. The graft functional and morphological evolution was assessed by ultrasound, magnetic resonance, electrophysiology methods, trans-illumination, and optic and electron microscopy investigations. Observation delays ran up to 12 months.
\end{abstract}

Results: In spite of uniformed implantation general conditions, graft survival and growth were hazardous and varied from 0 to $91 \%$ depending mainly on the implantation site. The best implant survival and development was observed in the ear pavilion subcutaneous site. An adult-like organ formed and was functional with morphologically normal cardiomyocytes. In the other sites development seemed to be slowed and remained incomplete, like stopped at an intermediary level.

Conclusion: Heterotopic foetal heart implantation into syngeneic adult different sites is feasible in the rat but gives non-homogeneous results. The graft development was complete only when implantation was realized in an ear pavilion subcutaneous pouch. Anyway the fetal heart implants could not be proposed for reparative heart surgery: they are too distant from the pericardium cavity to be used as a vascularized flap. The causes and implications of these differences in development of foetal heart implants are worthwhile further investigations, as well as means of improving their growth.

Keywords: Heart development; Heart transplantation; Fetal heart investigation; Fetal heart Implantation; Stem cells

Abbreviations: BW: Body Weight; FHI: Fetal Heart Implant/Implantation; IT: Ischemia Time; M: Mean Value; MRI; Magnetic Resonance Investigation; SD: Standard Deviation; USI: Ultra Sound Investigation

\section{Introduction}

First foetal heart transplantations were performed in the fifties and sixties of the 20th century [1,2]. But soon a moratorium forbidding any using of foetal material has practically stopped the researches and only few investigation results were published [3-12]. On the other hand, stem cell research has known an extraordinary interest, became an industry and allowed a great progress in the knowledge of intra and extra cellular organization, in the understanding of cell and tissue development. Their use was applied also to heart repair [13-22]. But the results of heart reparative trials were controversial $[14,15,19]$ and, at least for the 
moment, the clinical application of stem cell therapy is considered as successful mainly for tissue engineering and replacement $[23,24]$.

Interest for foetal heart transplantation did not disappear and developed after the end of the moratorium in 2009 [25 - 30]. But up to now "ethic" difficulties exist concerning human foetal organ procurement for therapeutic and even for scientific purposes, that partly explains the relatively rare publications on the topic. Nevertheless in vitro studies have limits when it becomes necessary to understand the complex relations between developing tissues, organs and systems within the living organism considered as a whole. These objectives would be realized with foetal organ transplantation - syngeneic as well as allogeneic and xenogeneic, as far as it is known that after implantation the foetal organ "regresses" and only later, after being vascularized, begins to grow and differentiate [31-33].

As a first step, the comparison of different foetal organ implantations in order to clarify the common and specific development pathways, the conditions of optimal development would open possible applications in fundamental and applied research.The present work is devoted to foetal heart syngeneic heterotopic implantation and aims to evaluate the techniques and the morphological development, as well as the functional capacities of the implants placed in different sites of syngeneic adult rat recipients.

\section{Material \& Methods}

The experiments were provided on 130 rats of Wistar and Fischer strains, both sexes, aged 2-4 months at the beginning of the study and BW 200-400g, displayed in 2 groups:

A. First - 55 animals (all implanted into the ear site) for determination of the influence of the duration of time between procurement and implantation ("ischemia" time /IT/)

B. Second-75 animals displayed in 7 series according to the site into which the foetal heart was implanted (Figure1) (Table 1).

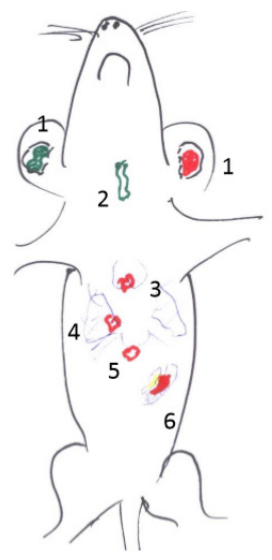

Figure 1: Sites of foetal heart implantation: 1 . subcutaneous ear pavilion site; 2 . between the muscles of the anterior part of the neck, 3. under the thymus capsule, 4. lung hila, 5; Marfan space; 6 . spleen hila and other localizations in the peritoneal cavity: omentum majus, ileocaecal region

Table 1:Experimental series in heterotopic transplantation of fetal heart (last series).

\begin{tabular}{|c|c|c|c|}
\hline SERIES (Sites of Implantation) & Number of Rats/Implants & Observation Delays (months) & Investigations \\
\hline Omentummajus & 10 & 4.5 & Histology \\
\hline Ileocaecal angle & 6 & 4.5 & Histology \\
\hline Thymus & 13 & 6.5 & USI, Histology \\
\hline Thoracic cavity & 18 & 6 & USI, Histology \\
\hline Lung hila or parenchyma & 15 & 2 & USI, Histology \\
\hline Pericardium & 2 & 6 & USI \\
\hline Marfan and submuscular spaces & 9 & 6 & USI \\
\hline Neck (between muscles) & 13 & 6 & Histology \\
\hline Ear pavilion subcutaneous pouch & 13 & $2-10$ & Histology \\
\hline TOTAL & 100 & &
\end{tabular}




\section{Surgery}

In all the animals anesthesia was induced by Isoflurane inhalation in a ventilator box ( $4 \%$ for $1 \mathrm{~min} / 100 \mathrm{~g} \mathrm{BW}$ ), followed by intra-peritoneal injections of Natrium pentobarbital (Nembutal ${ }^{\circledR}$ Ceva Santé animal- Brussels Belgium: $0.1 \mathrm{ml} / 100 \mathrm{~g}$ BW of a solution to $0.075 \mathrm{mg} / \mathrm{dl}$ ) during the surgical procedure. Buprenorphine hydrochloride (Temgesic $®$ - Laboratoire Schering-Plough Courbevoie France: $0.2 \mathrm{ml}$ of a $0.05 \%$ solution in intraperitoneal injection) was added for analgesia.In the cases of intrathoracic intervention Atropine (Lavoisier- Paris-France, $1 \%$ solution, $0.2 \mathrm{ml}$ independently on BW) in subcutaneous injection was administrated at least 5 minutes before intervention to avoid the occurrence of a vagal shock during the further manipulations. For intubation of the recipient the trachea was cannulated with a14G catheter with the help of a laryngoscope (Mac 0 blade-Heine Germany). An anesthesia-ventilation machine (Intermed-Penton, Sigma Delta, UNO-Netherland-USA) was used during the surgical procedure at a rate of 60 breaths/minute with a tidal volume at $12 \mathrm{ml} / \mathrm{kg}$ and a ventilation pressure of 0 to 20 milli Bars.

A. For fetal heart procurement the gravid female underwent laparotomy, the uterus was exposed and the foetuses (aged 1420 days in utero, BW 2-6g) were extracted. The anaesthesia and analgesia of the donors has been ensured by gravid female slight overdosing ( $0.2 \mathrm{ml} / 100 \mathrm{~g}$ of Nembutal). After wide thoracotomy the foetal heart was isolated and placed in a cup with saline at ambient temperature $\left(22^{\circ} \mathrm{C}\right)$. Within $10-30 \mathrm{~min}(15 \pm 5 \mathrm{~min})$ it was transferred to the recipient. So Ischemia time (IT) did not exceed $30 \mathrm{~min}$ that is important for the implant survival, as shown in preliminary series (Table 2).

\begin{tabular}{|c|c|c|c|}
\hline Series (ischemia Duration (min) & Initial Number of Implants & Implant Survival after 2 Weeks $\left(\%^{\circ}\right)$ & Implant Survival after 4 Weeks (\%) \\
\hline$<20$ & 31 & 100 & 100 \\
\hline $30-50$ & 53 & 100 & 91 \\
\hline $50-60$ & 16 & 94 & 66 \\
\hline$>60$ & 5 & 60 & 50 \\
\hline TOTAL & 105 (55 animals) & 88.5 & 76.75 \\
\hline
\end{tabular}

B. For foetal heart implantation into the ear pavilion, a skin incision was provided, a subcutaneous loge was managed by blind tissue separation and the implant was placed into the pouch. A Nobecutan(C) spray shut the incision. The procedure schedule was the same when implantation was performed into the neck or the Marfan-Pirogov-Larey space site, except that the skin was sutured by 2 or 3 separated stiches. In 10 animals, after division by scissors, the fetal heart implant was injected into the thoracic cavity through the thoracic wall by a thick needle (gauge 12).

For intrathoracic implantation, after median longitudinal sternotomy, the FHI was placed either into the thymus capsule or into the lung hila's under the visceral pleura. The incisions were shut by a $6^{\circ \circ}$ Ethilon stich. The thoracic wall wound was then sutured layer by layer with classic separate stitches using Vicryl $2^{\circ \circ}$ for sternum, $4^{\circ \circ}$ for muscles and diaphragm (if necessary) and running suture $6^{\circ \circ}$ for the skin.For intra-abdominal implantation, a longitudinal incision from sternum to pubis of the skin, the white line and the parietal peritoneum was performed. One or several FHI were inserted between the omentum sheets or into a loge managed under the visceral mesentery layer in the ileocaecal angle. Or in the spleen hilum An Ethylon $7^{\circ \circ}$ stich closed the pouch. The peritoneal cavity was shut by a two-layer suture using 4 or $5^{\circ \circ}$ Ethylon continuous suture.

\section{Animal follow up}

During the intrathoracic procedures the monitoring of cardiac and respiratory functions was ensured by a Mouse Monitoring device (UNO, Netherlands)Later, daily observation of the animals was realized up to 12 months after the operation; the animal body weight (BW) was measured at days 2, 5, 7, 14 and, after the initial BW recovering, once a month. The post operation investigations were:

A. Trans-illumination of the ear pavilion implantation site with a fiberscope FUJINON light source

B. ECG of the implants in ear site series, for control of the graft functional condition, ECG was performed on 10 animals with the help of an electrograph (Nicolet Biotechnical) through $1,2,4,6,9,11$ months after implantation. Needle-shaped electrodes were placed on both sides of the graft in the ear pavilion for registration of its electrical activity. The same kind of electrodes were inserted in the four members of the host for recording of its own ECG.

C. Ultra sound (USI) (apparatus IU22 -Philips - NL- with an ultrasonic probe (L17-5 MHz), at month 2, 46 for implant localization after intrathoracic and intraabdominal implantation. 
D. Magnetic resonance (MRI) of the ear pavilion at 2 and 4 months after FHI, with a Philips GyroscanIntera 1.5 Tesla and a circular surface coil (Philips C64 or micro-antenna 12mm*) added. Slice thickness was $0.5 \mathrm{~mm}$. The visualization of the implant movements was realized thanks to an echo gradient sequence (EG) that was less sensitive to the movement artefacts and very weighted in T2. That gave an important contrast between the heart wall and the luminal fluid (identified as blood not only because of its non-homogeneous structure, but also thanks to the correspondence of MRI images with histological pictures). The use of B-FFE sequence was determinant for reaching this effect.

E. Coupling of image acquiring and cardiac rhythm was revealed quite difficult because of the high frequency of the recipient heart beating (till 200-250 per $\mathrm{min}$ ). For the implant movement detection, acquiring of several dynamic slices at the same place to recreate movement in cine mode was efficient. So RT (repetition time) had to be twice the echo time (ET) in such a way as the 3 gradients $(\mathrm{W}, \mathrm{Y}, \mathrm{Z}$ ) were in one phase before the next weighting: flow compensation must be realized with a constant speed to reinforce the signal of moving fluids. Sensibility to the main magnetic field heterogeneity and to chemical shift must be present, especially for ET chosen between 2.2 and $2.8 \mathrm{~ms}$.

F. NB. All the investigations were provided under light anesthesia by intra peritoneal injection of Pentobarbital Sodium (Nembutal®: $0.1 \mathrm{ml} / 100 \mathrm{~g}$ BW of a solution to $0.075 \mathrm{mg} / \mathrm{dl}$ ).

G. Histological investigation: after each animal death or euthanasia (by anesthetic overdose), that is at days $0,2,5$, $7,14,21,28,42,60$ and at months 4, 6, 7-12, macroscopic and microscopic investigation of the transplantation area and main inner organs (lungs, liver, kidneys) was provided. Collected biopsy materials were fixed in neutral buffered formaldehyde $4 \%$ and embedded in paraffin. Three microns slices were stained by hematoxylin eosin and in some cases by trichrome green of Masson for microscopic evaluation. Electron microscopy of the grown graft was performed using $1.5 \%$ glutaraldehyde fixation and epon embedment.

\section{Statistics}

The results are given as Mean \pm Standard Deviation $(\mathrm{M} \pm \mathrm{SD})$. The reproducibility of the measuring techniques was expressed as the coefficient of variation of repeated measurements ( $V=S D / M \%)$. Statistical significance of differences was assessed by Student's test versus control series ( $\mathrm{td}<\mathrm{t}$ standard).

\section{Animal's Management}

Before, during and after the experimentation animals were managed in a recognized animaly (LA 1230439) according to the rule's instruction of Belgian CEBEA 2013, modified in 2018. Taking into account the importance of surgery and its possible consequences, for instance in competition for food, the animals were kept in individual cages type 3 . The nutrition conditions were standardized all through the experiment with the use of "food for breeding" (A04, "Safe"; France) and of fresh water as drink.The experiments were authorized by the local Committee of Animal Welfare (protocols $\mathrm{N}^{\circ} 50$ and 508).

\section{Results}

Rat sex, strain and age did not seem to influence the obtained results.FHI implantations into the thymus, Marfan-Larey-Pirogov space, between mesenteric layers of omentummajus or ileo-caecal region, ear or neck sites were well tolerated but a foetal organ growth was not always observed (Table 3).In the different sites of the abdominal cavity, very small remnants $(1 \times 2 \mathrm{~mm})$ of the implants could be identified within the epiploic sheet ( 2 cases) and under the mesenteric layer of the ileo-caecal region (2 cases). This development was quite limited and did not reach a cardiomyocyte differentiation and organization even within 4-6 months (Figure 2).

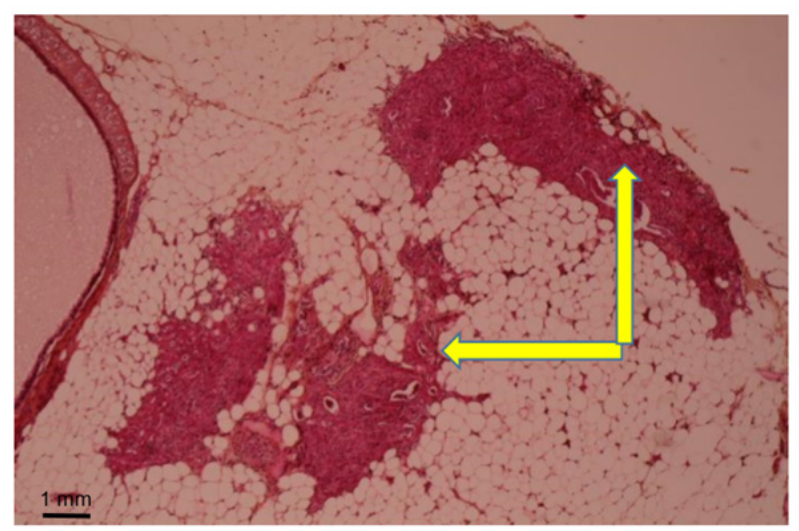

Figure 2: Month 3: Weak development of foetal heart implant (arrow) in mesenteric pouch (Hematoxylin eosin). 
Table 3: Results of heterotopic implantation of fetal heart.

\begin{tabular}{|c|c|c|c|c|}
\hline Series (sites of Implantation) & Recipient number & Recipient survival & Complications & Implant growth number \\
\hline Omentummajus & 9 & 8 & 1 anaesthesia & $4 ?$ \\
\hline Ileocaecal angle & 6 & 5 & 1 anaesthesia & 3 \\
\hline Thymus & 13 & 12 & 1 anaesthesia & 4 \\
\hline Thoracic cavity & 18 & & 3 Hemoesthesia 1 pneumothorax & \\
\hline Lung hila or parenchyma & 15 & 7 & 0 & 0 \\
\hline Pericardium & 2 & 2 & pneumoperitoneum (diaphragm wound) & $1 ?$ \\
\hline Marfan and submuscular spaces & 9 & 7 & 0 & 10 \\
\hline Neck (between muscles) & 13 & 13 & & 13 \\
\hline Ear pavilion subcutaneous pouch & 13 & 13 & & 38 \\
\hline TOTAL & 100 & 67 & & \\
\hline
\end{tabular}

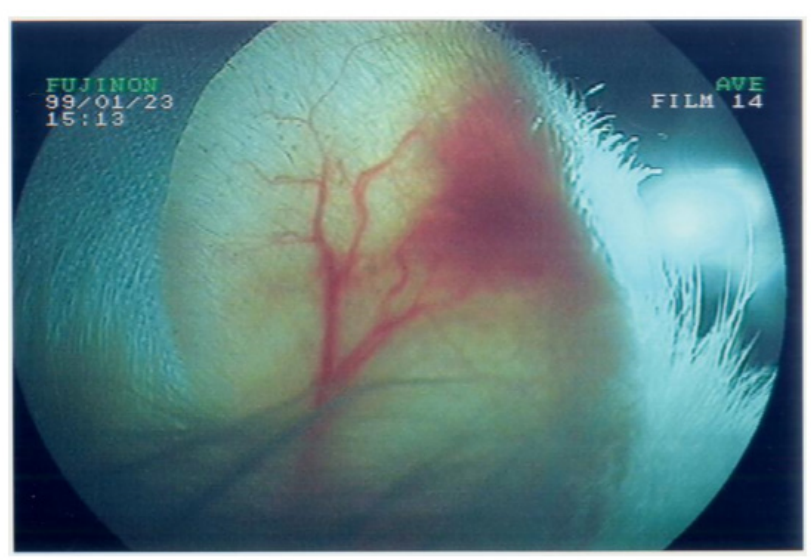

Figure 3: Development of a foetal heart implant an the ear site viewed by trans-illumination

Within the thoracic cavity implantation of FHI under the visceral pleura was technically too delicate, causing either haemorrhages or air exit uneasy to stop and leading to not controlled pneumothorax. A beginning of FHI development detected by USI, was observed in 4 cases under the mediastinal pleura of the lung hila's (but histology was not convincing), and, in 3 cases under and on the thymus capsule. But within the implant neither cavity nor differentiation into functional cardiomyocytes could be observed.The best results were obtained in neck and ear sites of implantation with the development of an organoid measuring more than $2 \times 2 \mathrm{~mm}$ up to $6 \times 5 \times 3 \mathrm{~mm}$ and $7 \times 8 \times 4 \mathrm{~mm}$ (Figure 3).

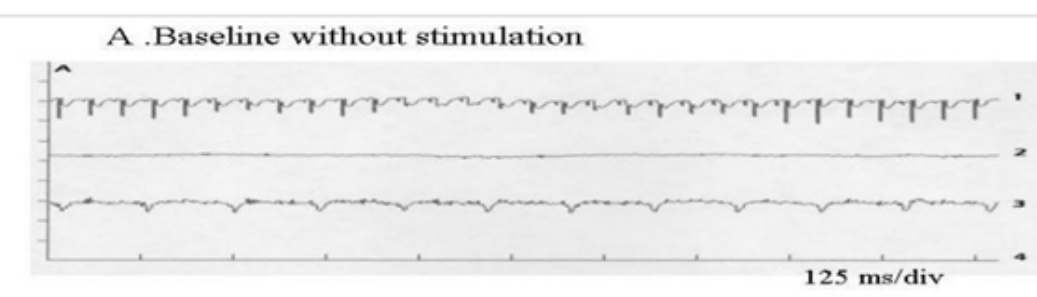

B.After adrenaline $0,1 \%-0,1 \mathrm{ml}$ i.p.injection in the host

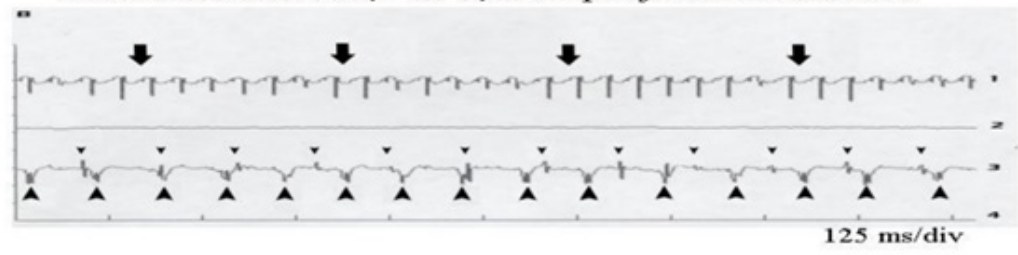

Figure 4: Functional evolution of a foetal heart implanted into a subcutaneous pouch in the ear pavilion at months 4-8 


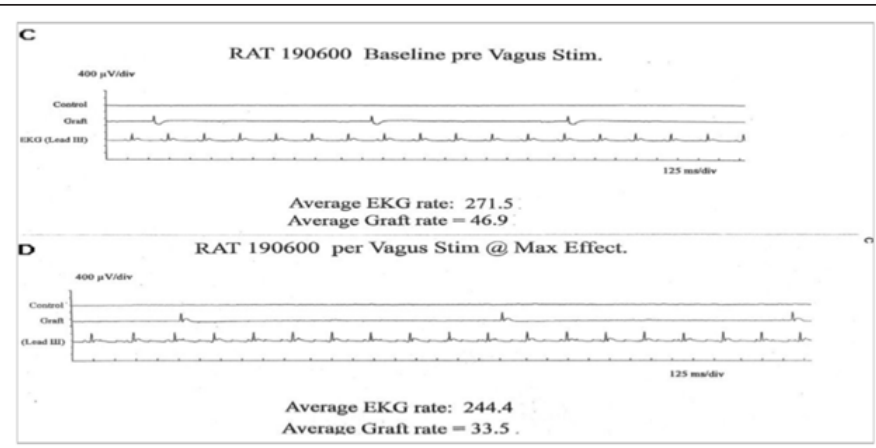

Figure 4A: Registration of electric activity and demonstration of the capacity of the implant to answer to neuro-humoral stimulations

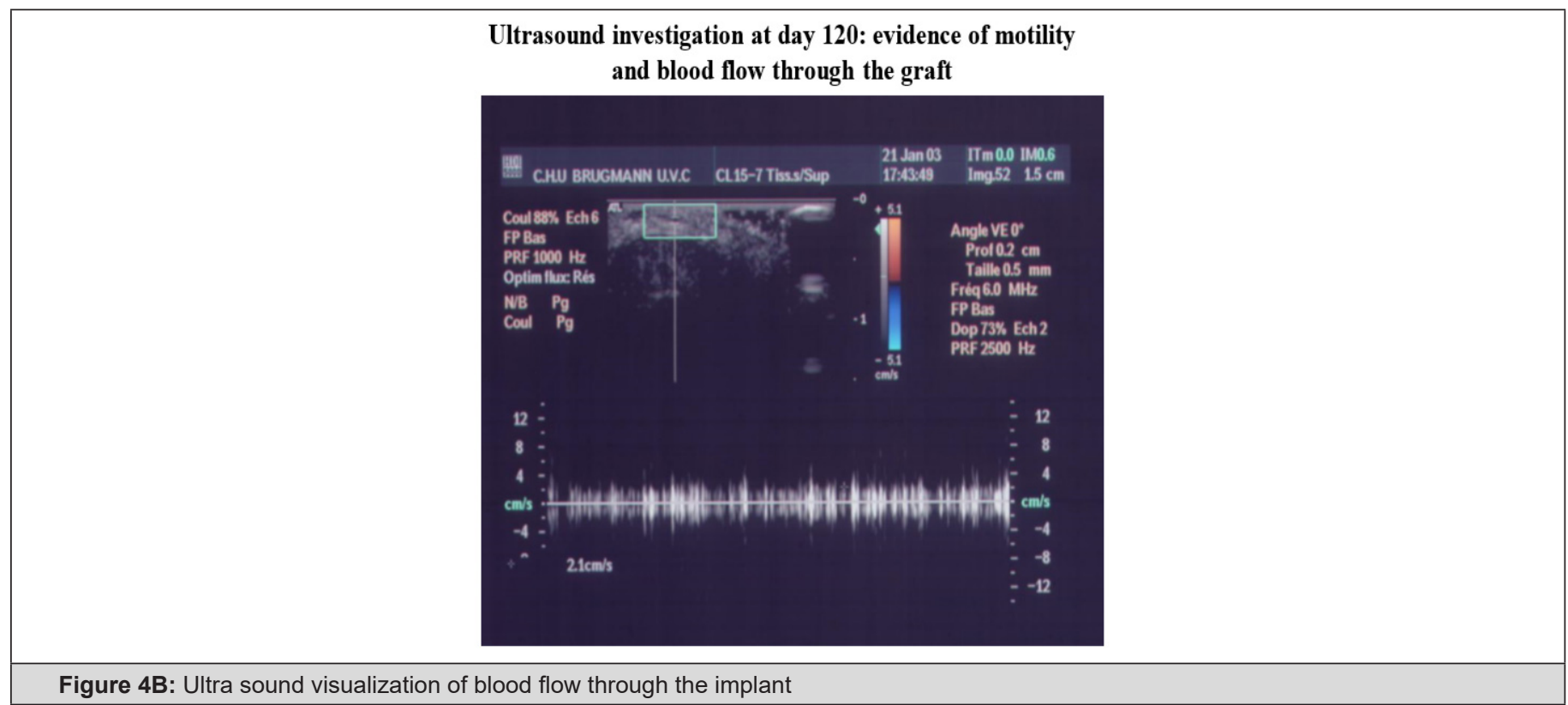

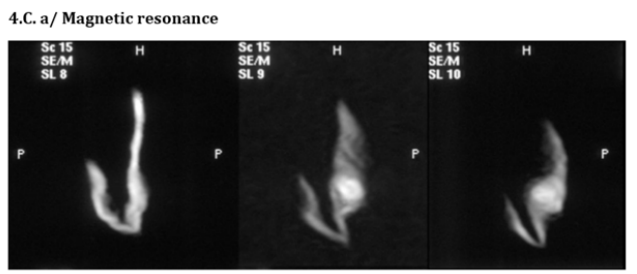

4.c. b/

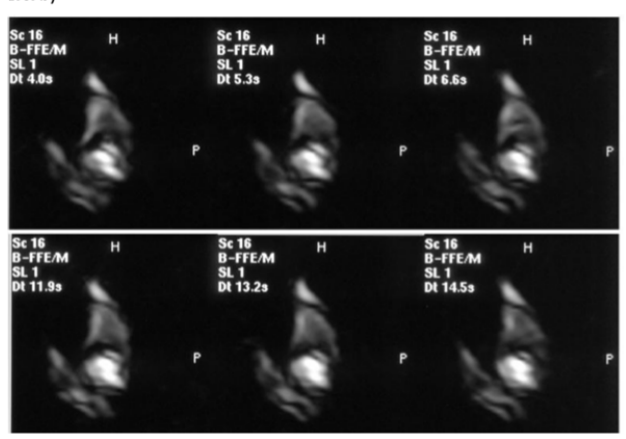

4.C.c/

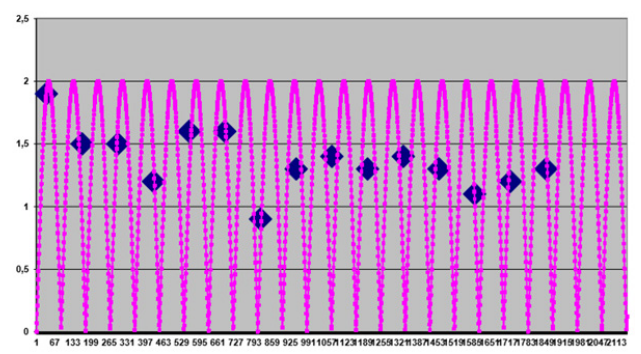

Figure 4C: Magnetic resonance investigation: evidence of blood circulation through the implant and a cardiac rhythm (78/min) From above to beneath: a/ static mode registration with a slice thickness of $0.5 \mathrm{~mm}, \mathrm{~b} /$ dynamic mode registration, $\mathrm{c} /$ determination of cardiac rhythm by alignment of the positions of one fixed point on a determined rhythm of oscillations 


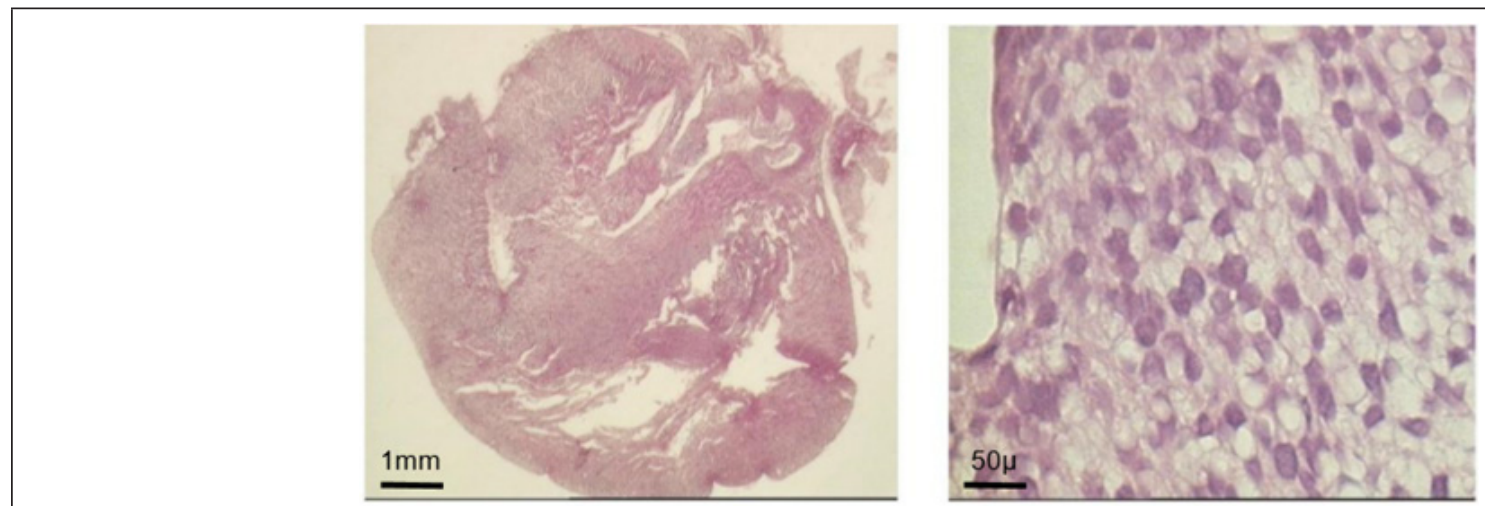

Figure 5A: Morphological evolution of fetal heart implanted into a subcutaneous pouch of the ear pavilion. (haematoxylin eosin). Before implantation
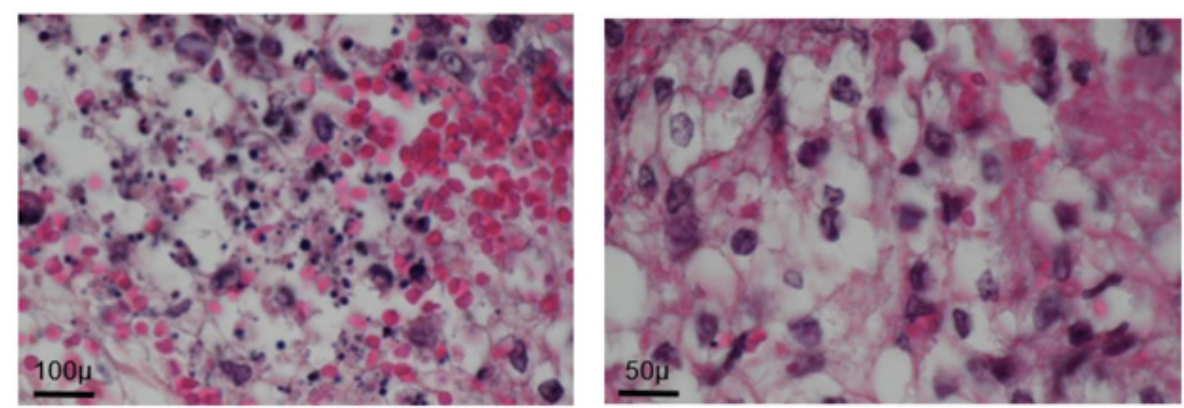

Figure 5B: At day 4: some cardio-myoblasts among necrotic and undifferentiated cells
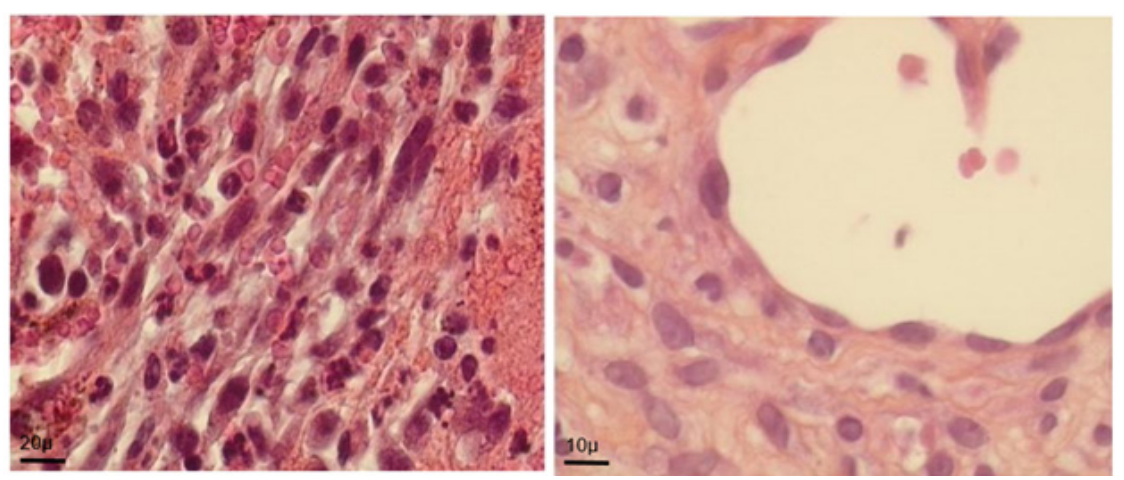

Figure 5C: At day 8: formation of a lacuna bordered by endothelium
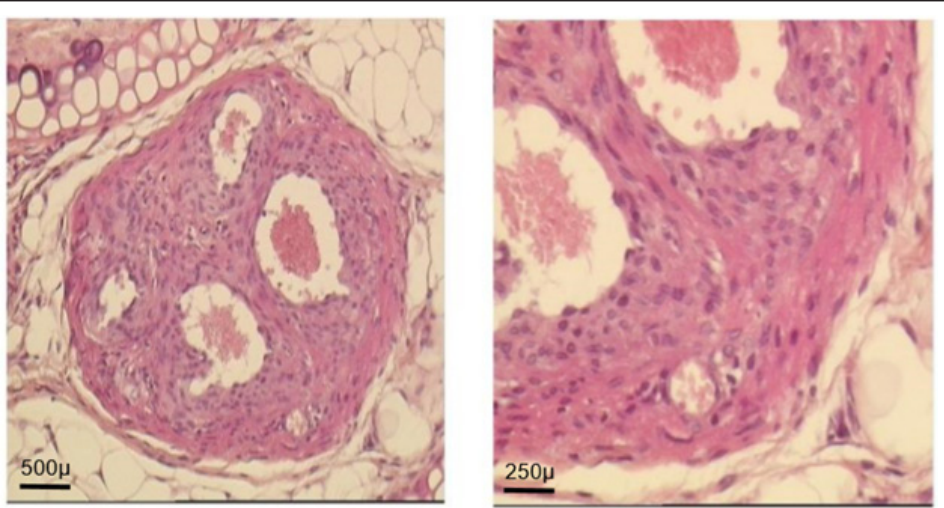

Figure 5D: At day 30: ventricle like formation with mature cardio-myocyte, endocardium and epicardium 

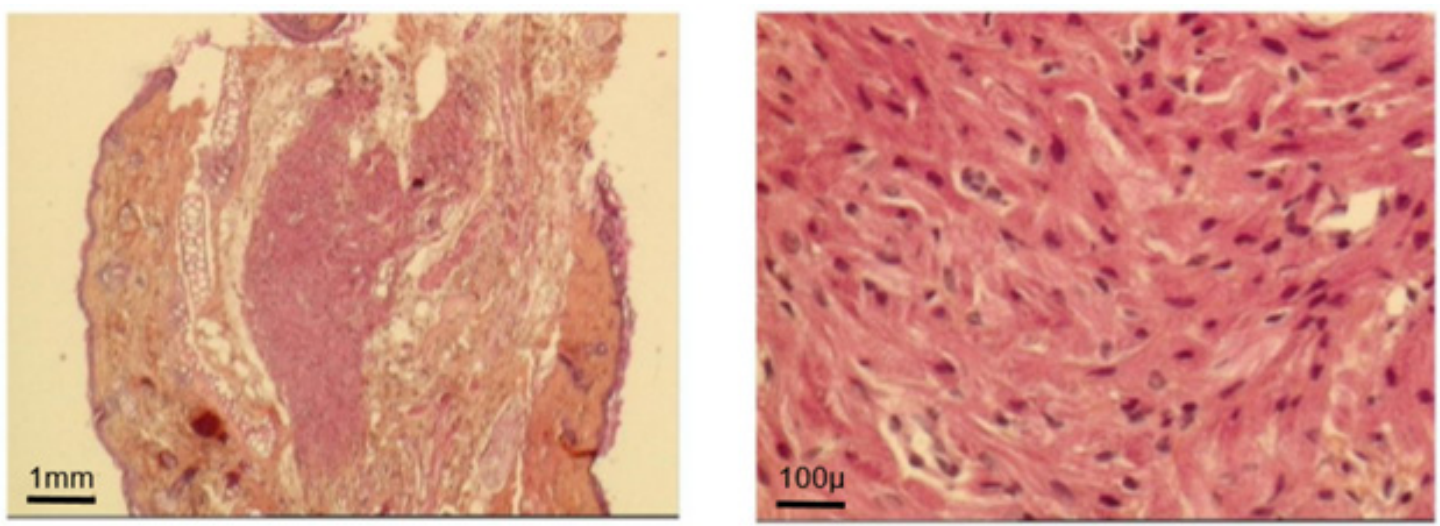

Figure 5E: At month 3: implant (arrow) mature cardiomyocytes

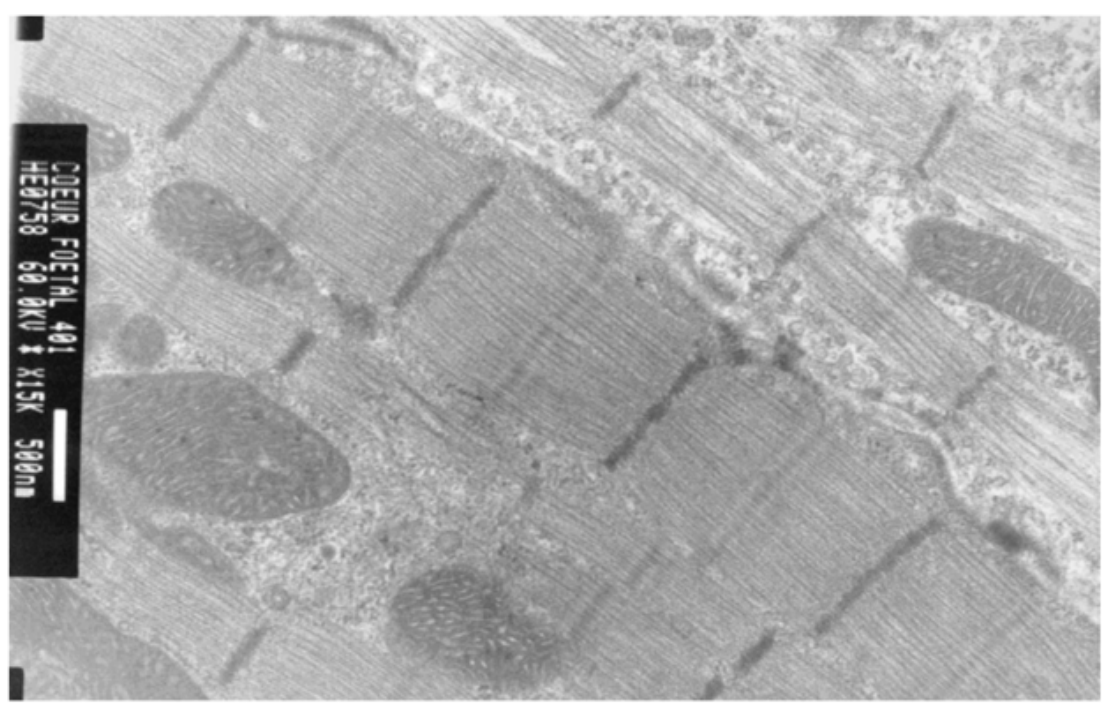

Figure 5F: At day 160: normal adult ultra-structure of fetal implant cardiomyocyte
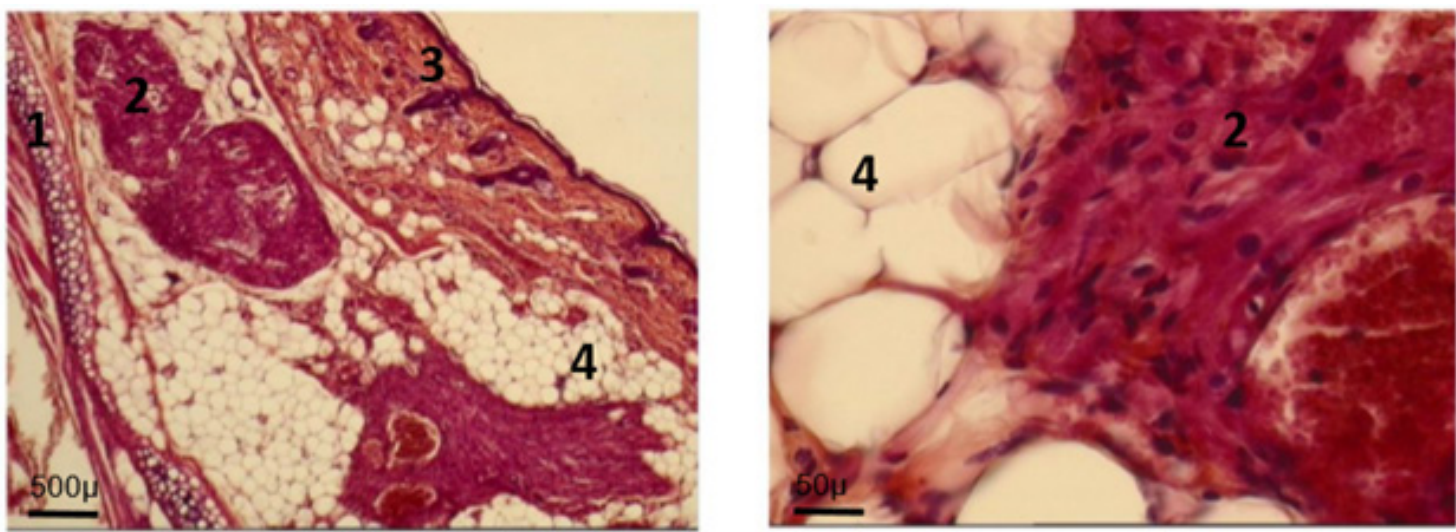

Figure 5G: At day 160: normal adult ultra-structure of fetal implant cardiomyocyte.Ear cartilage; 2. Implant; 3. Ear skin; 4. Adipose tissue

Such an implant was able to contractile activity different from the host one (much slower: 70-80 instead of 350-450 beatings/ min), as revealed by ECG registration (Figure 4A). It was also able to ensure blood flow through it, as shown by USI and MRI investigations (Figure 4B \& 4C).At the ear site, as shown in our early investigations, the implant evolution of the foetal heart implant was the following: during the first week "regression" to a mass of necrotic cells (infarct), undifferentiated cells and foetal erythrocytes 
among which some living cardio-myoblast were observed (Figure 5A \& 5B). During the following 3-4 weeks a ventricle-like formation with normal cardio-myocytes developed and was able to have a normal function i.e. electrical activity modified by adrenergic and vagal influences, contractions able to propel blood through the cavities and ensure a blood flow assessed either by USI and MTI investigations (Figure 4B \& 4C) [29,30]. In late delays, after 8 months post-surgery, the progressive replacement of myocytes by adipocytes was noted evoking an aging evolution (Figure 5C - 5G).

\section{Discussion}

The present work does not pretend to be exhaustive in the investigation of the topic. We did not explore subscapular FHI into the spleen or the kidney, because it was far from giving possibilities of clinical applications for heart lesion repair that is the end aim of the research in this field.Nevertheless, analysis of its results shows that, in similar conditions of graft procurement, surgery duration, post-operative management, the difference in implant growth and maturation was indubitable and depended on the site which the foetal heart was implanted into. One of the possible explanations of the phenomenon may be difficulties of re-vascularisation of the implant placed in the only contact with serosa: pleura, peritoneum.

This is corroborated by better results observed when the implant was placed between the neck muscles or under the thymus capsule in our and other authors' experiments [2], But it remains not quite clear why the ear pavilion site has conditioned the complete development of implanted foetal heart. Would a question of vascularization or innervation peculiarities of the site be envisaged? Only FHI into a skeletal muscle [4], in the anterior eye chamber [5.6] and under the kidney capsule [27] had given similar results. Besides these loci are rich in blood vessels. Comparison with other foetal organ heterotopic implantation (oesophagus, stomach, intestines, pancreas and liver) confirms the favourable properties of the ear pavilion site to growth and differentiation of foetal implants [8,33-38].

Comparison with orthotopic FHI shows quite different results than heterotopic: maturation of the graft cells but no organoid formation and autonomy in our observations [28-30]. It is to be noted that other authors have obtained the formation of an autonomous functional organoid, negatively interfering with the recipient heart function $[18,19]$. But the implant seemed to have been grown first in vitro, using foetal heart stem cells.

It is sure that environment conditions, such as possibilities of re-vascularization, re-innervation, volume expansion, growth factor mobilisation and other, maybe presently unknown, must have an influence on the FHI and other foetal organ graft development. Their investigation is worthwhile further fundamental studies. In this field expertise of in vitro stem cell cultures may be useful [39].
Some preliminary trials in this direction - investigation of IGF-1 and PTHrP variations after foetal organ implantations - were provided but need further development $[41,42]$.

As to practical applications of heterotopic FHI, presently it cannot be proposed for clinical use in heart lesion repair because - when a significant development is obtained, the graft or part of it cannot be transplanted with its vascular peduncle safe or able to be anastomosed to a local blood vessel, as it was realized for oesophagus repair[44]. If the FHI development is still incomplete, (as in the case of sub-serosa implantation) and an immediate revascularization is not crucial for the graft, the situation is similar to fetal pancreatic graft $[45,46]$ and it might be interesting to try displacing this FHI to le lesion site for dressing. But it would be also the aim of further investigations [45].

\section{Conclusion}

1. Heterotopic implantation of a foetal heart into different sites of a syngeneic adult rat is feasible but gives different results depending on the implant localization.

2. The best results were obtained when the foetal heart was implanted into a subcutaneous pouch of the ear pavilion, i.e. development of an adult like ventricle with normal functional ability and morphology.

3. Presently the heterotopic implantation of a foetal heart cannot be proposed for reconstructive medicine applications.

4. Further investigations of the origin of the observed differences in the implant heterotopic development and of the means able to improve or control the implant growth are worthwhile.

\section{Acknowledgement}

The authors express their thankfulness to:The Foundation for Cardiac Surgery and the Institute of Pathology and Genetics for precious material and moral support, Professors G. Primo, P. Wauthy, P. Deltenre and P. Bergmann (Foundation for Cardiac Surgery; CHU Brugmann; ULB) for scientific support, MrsA. Bekkouri Richa and M. Régnault, MsE.Beckers, G van de Gucht and N Lopez for their precious technical help and support, Ms M Leroy (IPG) and Mr J-L Kempeneers for important logistic support.

\section{References}

1. Poor E (1957) Brephoplastichomotransplantation of hamster heart: a preliminary report. Transpl Bull 4(4): 143-144.

2. Fulmer RI, Cramer AT, Liebelt RA, Liebelt AG (1963) Transplantation of cardiac tissue into the mouse ear. Am J Anat113(2):273-285.

3. Wegmann TG, Melnychuk W (1976) Influence of multiple syngeneic fetal heart grafting on individual graft survival. Nature 264: 558-560.

4. Jockusch H, Mehrke G, Frichtbauer E (1983) Beating heart muscle in a skeletal muscle bed. Exp Neurol 81(3): 749-755. 
5. Tucker DC, Snider C, Woods WT Jr (1988) Pacemaker development in embryonic rat heart cultured in oculo. Pediatr Res 23(6): 637-642.

6. Bishop SP, Anderson PG, Tucker DC (1990) Morphological development of the rat heart growing in oculo in the absence of hemodynamic work load. Circ Res 66(1): 84-102.

7. Yao M, Dieterle T, Hale SL, Dow JS, Kedes LH, et al. (2003)Long term outcome of fetal cell transplantation on postinfarction ventricular remodeling and function. J Mol Cell Cardiol 35(6): 661-670.

8. Coulic V, Hustin J, Novikov V (1996) Morphofunctional peculiarities of ectopic fetal pancreatic growth. Acta Gastroenterologicabelgica 59: C 62.

9. Coulic V, Deltenre P, DePrez C, Pegnyemb M, Staroukine M (1999) Ectopic growth of fetal heart implant. Acta clinicabelgica 54(2): 103.

10. Coulic V, Deltenre P, Beckers, DeReuck M, Krzemien M, et al. (2000) Morphological and physiological features of ectopically grown feta heart implants. Sociétébelge de Médecine interne. Acta Clinica Belgica.

11. Coulic V, Collette J, Deltenre P, DePrez C, DeVuyst M, et al. (2001) Cardiomyoblasts implantation (First results). XIVth ISDQP International Congress. Diagnostic molecular pathology: from genomics to proteomics. Proceedings, pp.66.

12. Etzion S, Battler A, Barbash IM, Cagnano E, Zarin P, et al. (2001) Influence of embryonic cardiomyocyte transplantation on the progression of heart failure in a rat model of extensive myocardial infarction. J Mol Cell Cardiol 33(7): 1321-1330.

13. Li RK, Weisel RD, Mickle DA, Zhang J, Mohabeer MK (1996) In vivo survival and function of transplanted cardiomyocytes. Circ Res 78(2): 283-288.

14. Li RK, Jia ZQ Weisel RD, Mickle DA, Zhang J, et al. (1996) Cardiomyocyte transplantation improves heart function. Ann Thorac Surg 62(3): 654661.

15. Sakakibara Y, Tambara K, Lu F, Nishine T, Nagaya N, et al. (2002) Cardiomyocyte transplantation does not reverse cardiac remodeling in rats with chronic myocardial infarction. Ann Thor Surg 74(1):25-30.

16. Gulbins H, Meiser BM, Reichenspurner H, Reichart B (2002) Cell transplantation - a potential therapy for cardiac repair in the future?. Heart Surg Forum: 5(4): E28-E34.

17. Hiel JM, Dick AI, Raman VK, Thompson RB, Yu ZX, et al. (2003) Serial cardiac magnetic resonance imaging of injected stem cells. Circulation 108(8): 1009-1014.

18. Ménasché $P$ (2003) Cell transplantation in myocardium. Ann Thorac Surg 75(6): 20-28.

19. Lebon B, Garcin I, Ménasché P, Vilquin JT, Audinat E, et al. (2003) Myoblasts transplanted into rat infarcted myocardium are functionally isolated from their host. Proc Natl Acad Sci 100(13): 7808-7811.

20. Jaquet K, Krause KT, Denschel J,Faessler P, Nauerz M, et al. (2005) Reduction of myocardial scar size after implantation of mesenchymal stem cells in rats: what is the mechanism? Stem cell Dev 14(3): 209-309.

21. Von Laake L, Hassing R, Doevendans PA, Mummery C (2009) Heart repair and stem cells. J Physiol 577(2): 467-478.

22. Irion S, Nostro MC, KattmanSJ, Keller GM (2008) Directed differentiation of pluripotent stem cells: from developmental biology to therapeutic applications. Cold SprinfHarbSymp Quant Biol 73: 101-110.

23. Chien KR, Frisen J, Danielson R, Melton DA, Murry CE, et al. (2019) Regenerating the field of cardiovascular cell therapy. Nat Biotechnol 37(3): 232-237.

24. Zakrzewski W, Dobrtzinski M, Szymonowicz M, Rybak Z (2019) Stem cells: pasr, present and future. Stem cell Res Ther 10: 68.
25. Coulic V, Collette J, Deltenre P, DePrez C, DeVuyst M, et al. (2001) Cardio myoblast implantation (First results). Proceedings of the XIVth ISDQP International Congress. Diagnostic molecular pathology: from genomics to proteomics pp. 66.

26. Damry N, Hermanus N, Régnault M, Coulic V, Staroukine M, et al. (2005) Magnetic resonance in the evaluation of a fetal heart implant in the Rat. Actes Sciences, Technologie et Imagerie, Nancy Pp. 39-40.

27. Zhang EY, Xiong Q, Ye Lei, Suntharalingam P, Wang X, et al. (2012) Fetal myocardium in the kidney capsule: An in vivo model of repopulation of myocytes by bone marrow cells. PLoS One 7(2): 31099.

28. Coulic V, Delrée P, De Prez C, Novikov V, Quéron S, Vandaele S (2013) Fetal organ transplantation as a step-in regenerative medicine. BIT's $1^{\text {st }}$ Annual Global Health Conference, RMSC $6^{\text {th }}$ World Congress, Dalian Abstracts pp.707.

29. Quéron S, Coulic V, Delrée P, Najar ES, Bergmann P (2015) Fetal heart transplantation: influence of some factors. ESOT pp. 447.

30. Quéron S, Delrée P, De Prez C, Najar ES, Coulic V (2016) New hopes in the use of fetus as a donor for fetal heart implantation on the surface of a heart lesion (first experimental results). Bit's $10^{\text {th }}$ Annual Meeting of Regenerative Medicine and Stem Cells. Nanjing pp.15-17.

31. Coulic V, Collette J, DeVuyst M, Hustin J, DeKoster E (2001) The first phase of the syngeneic fetal organ implant development: crucial and mysterious process. Abstracts $14^{\text {th }}$ Heidelberg Cytometry Symposium (HCS) pp. 18-20.

32. Coulic V, Novikov V, Delrée P (2017) Surgical models of in vivo culture stem cell by implantation of fetal organs into adult animals. International Journal of Surgery and Transplantation Research 1(4): 34-44.

33. Coulic V, Hustin J, DeVuyst M, DePrez C, Staroukine M, et al. (1999) Degenerative and regenerative processes in fetal organ ectopic growth. Analytical Cellular Pathology 18(1): A 046.

34. Isrkenko IA.Novikov VK, Sidi B, Staroukine MA (2005) Experimental comparative evaluation of the functional capacities of ectopically grown fetal organs. Ross FiziolZhIm I M Sechenova 91(4): 408-430.

35. Coulic V, Novikov V, Pissareva T (1988) Transplantation of fetal pancreas. Abstracts of the 1st International Congress on pancreatic and islet transplantation 27-29: 227.

36. Coulic VP, Novikov VK, Pisareva TP (1989) Fetal pancreatic grafting Diabetes. 38(1): 317.

37. Coulic VP, Novikov VK, Iskrenko IA, Naoumetz LV (1994) Transplantation of the foetus small intestine to adults' animals. Sechenov Physiological Journal 80(8): 73-87

38. Coulic V, Delrée P, DePrez C, Bakari S, Lasser L, et al. (2003) Fetal liver syngenic transplantation (First report) XVth Belgian Week of Gastroenterology (Abstracts), Acta Gastro-enterologicaBelgica 66(1): B 01.

39. Daoud A, Mùnera JC (2019) Insights into human development and disease from human pluripotent stem cell derived intestinal organoid. Front Med (Lausanne) 6:297.

40. Coulic V, Collette J, DePrez C, DeVuyst M, Hustin J, et al. (2000) Ectopically growing fetal organ implants and growth factors. ICHC 2000, XIth International Congress of Histochemistry and Cytochemistry. 105: N 3.

41. Coulic V, Collette J,Hustin J, DeKoster E, Deltenre M (2001) Growth factors and fetal digestive organ implants development. Acta gastroenterologicaBelgica64(1): B2.

42. Coulic V, DeWolf N, Scheen R, Delrée P, DeKoster E, et al. (2006) Influence of implantation and ectopic development on the expression of PTHrP and PTH/PTHrP receptors in fetal rat intestine grafts. Acta Belgica Gastroenterologica 69(1): B01. 
43. CF Teng, LB J and WC Shyu (2018) Role of insulin-like growth Factor receptor signaling in stem cell-stemness and therapeutic efficacy. Cell Transplant 27(19): 313-318.

44. Vandaele S, Najar ES, Delrée P, DePrez C, Maquet V, et al. (2018) Combined bio-prosthesis for oesophagus defect repair (Experimental study). EC Gastroenterology and Digestive System 5(11): 854-871.
45. Coulic V, Delrée P, Duprez C, Deltenre P, Novikov V, et al. (2008) Fetal digestive organ transplantation: comparative peculiarities and possible clinical applications. Gut, 16 ${ }^{\mathrm{TH}}$ UEGW Viena, 57(II): A157, P0261.

46. Coulic V, Novikov V (2017) Has fetal whole fetal pancreas grafting some perspectives among the surgical methods of diabetes mellitus treatment? J Endocrinol \& Thyr Research 1(3): 2573-2188. 